\title{
Crustal structure of the central Tibetan plateau and geological interpretation*
}

\author{
Can Ge $\mathrm{Ge}^{1,2,3, \star} \quad$ Youshun $\mathrm{Sun}^{3} \quad$ M Nafi Toksöz ${ }^{3} \quad$ Yingcai Zheng $^{3}$ \\ Yong Zheng ${ }^{1} \quad$ Xiong Xiong ${ }^{1}$ and Diming $\mathrm{Yu}^{3}$ \\ ${ }^{1}$ State Key Laboratory of Geodesy and Earth Geodynamics, Institute of Geodesy and Geophysics, \\ Chinese Academy of Sciences, Wuhan 430077, China \\ ${ }^{2}$ University of Chinese Academy of Sciences, Beijing 100049, China \\ ${ }^{3}$ Department of Earth, Atmosphere and Planetary Sciences, Massachusetts Institute of Technology, \\ Cambridge, MA 02139, USA
}

\begin{abstract}
Based on teleseismic data obtained from 225 stations from two networks in the central Tibetan plateau, we have generated detailed crustal structure images using P-wave receiver function techniques with more accurate piercing-depth-correction and time-depth-correction than what have previously been available. Our images indicate an undulatory Moho beneath the Tibetan plateau with a steep jump beneath the northern Himalaya, and obviously different structures in proximity to the Bangong-Nujiang suture. In several sections of the Tibetan plateau, the lower crust is characterized by pervasive high-velocity regions, which are consistent with the preservation of eclogite bodies beneath the plateau, whose presence affects the dynamics of the Tibetan plateau.
\end{abstract}

Key words: receiver function; crustal structure; Tibetan plateau

CLC number: P315.2 Document code: A

\section{Introduction}

The Tibetan plateau is a unique feature on the Earth's surface due to its towering, vast topography. Despite decades of study, the question of how it attained and maintained its extreme elevations (reaching $\sim 5000$ meters) remains a hot debate. Different mechanisms, such as whole or partial crustal-shear deformation (Houseman and England, 1996), middle to lower crustal flow (Clark and Royden, 2000; Royden et al., 2008; Zhang et al., 2010), oblique uplift along faults (Molnar and Tapponnier, 1975; Tapponnier et al., 2001), vertical rock-mass transformation (England and Houseman, 1986; Le Pichon et al., 1992) and others (Powell and Conaghan, 1973; Chung et al., 2005), have been presented to explain the observed uplift history

\footnotetext{
* Received 18 October 2012; accepted in revised form 6 November 2012; published 10 December 2012.

* Corresponding author. e-mail: gecan2008@gmail.com

(c) The Seismological Society of China, Institute of Geophysics, China Earthquake Administration, and Springer-Verlag Berlin Heidelberg 2012
}

and crustal thickness of the Tibetan plateau. Unfortunately, it is hard to say which mechanism(s) is/are better than others from surface surveys alone. We propose, however, that by comparing current crustal structures, as well as predicted structures from different models, we can identify a/several reasonable geodynamic scenarios. In this pursuit, we must first obtain a detailed deepinterior structure of the Tibetan plateau lithosphere.

An increasing number of seismic experiments have been operated on the Tibetan plateau over the last 30 years (e.g., Kosarev et al., 1999; Kao et al., 2001; Wittlinger et al., 2004; Kumar et al., 2005, 2006; Singh and Kumar, 2009; Tseng et al., 2009). The fundamental structures that compose the lithosphere under the extreme topography of the Tibetan plateau have been gradually discovered over time, allowing us to work towards deciphering the geodynamic mechanisms that have led to the growth of the plateau. The subducting Indian lithosphere is northward-thrusting under the Tibetan plateau at an increasingly shallow angle, and reaches progressively further toward the Jinsha suture in western Tibet, the Bangong-Nujiang suture in the 
center, and the middle of the Lhasa terrane in the east, which has been resolved using receiver function and travel-time tomography studies ( $\mathrm{Li}$ et al., 2008; Kind and Yuan, 2010; Zhao et al., 2010; Zhao et al., 2011). In the Himalaya and the central Tibet, doublet crustal structures are presented (Kind et al., 2002; Schulte-Pelkum et al., 2005; Nábělek et al., 2009; Wittlinger et al., 2009), which partially explains approximately $2000 \mathrm{~km}$ of post-collision convergence between India and Eurasia (Molnar and Tapponnier, 1975; Patriat and Achache, 1984; Besse and Courtillot, 1988; Patzelt et al., 1996; Yi et al., 2011). The lower crust, which exhibits characteristic high shear wave velocities and low $v_{\mathrm{P}} / v_{\mathrm{S}}$ ratios, is related to the transformation of the subducted Indian crust to dense eclogite facies material (Spain and Hirn, 1997; Schulte-Pelkum et al., 2005; Wittlinger et al., 2009). Does this vertical transformed structure exist pervasively throughout the Tibetan lower crustal section, or is it only focused within the India subduction range? If the latter is true, why is the remaining lower crust at the same depth not eclogitized? Nevertheless, as the Tibetan plateau was sutured by several micro-continents, is there any different in depth between these suture areas and the core of the micro-continents? Detailed crustal structure images of the Tibetan plateau may give a clue to these answers.

In the Tibetan crustal stratum, there are several major impedance interfaces that we may use to investigate underlying structures. The fundamental one is the Moho interface, which marks the transition of gabbroic lower crust to olivine-rich mantle. Another is the Conrad discontinuity, which separates continental upper Si-Al crust from the underlying lower Si-Mg crust, and represents a major change in seismic velocities as well as chemical composition. Large velocity impedances also exist where crustal material is juxtaposed alongside high-density eclogite facies material in the lower crust. We obtained this structural information from teleseismic records by receiver function techniques (Langston, 1979). P-wave receiver functions, obtained by deconvoluting the vertical seismogram from rotated radial and tangential seismograms from teleseismic earthquakes, emphasize $\mathrm{P}$ - to S-wave conversions generated at these deep impedance contrasts and can be used to interpret structures. Here we use different frequency receiver functions of tele-seismograms, recorded by the project INDEPTH (International Deep Profiling of the Tibet and the Himalaya) and the project HiCLIMB (Himalayan-Tibetan Continental Lithosphere during Mountain Building), to attain a detailed image of crustal structure at $10-100 \mathrm{~km}$ depth within the center of the Tibetan plateau with finer pierce-point and ray-parameters adjustments at each 10-km-depth section.

\section{Geological setting and stations distribution}

The Tibetan plateau consists of at least four fragments, which were accreted to the southern margin of Asia during different times (Chang et al., 1986). The stations we used in this study were located within three of these fragments. From south to north, these fragments are the Qiangtang, Lhasa and Himalaya terranes, separated by the Bangong-Nujiang suture (BNS) and Yarlung Zangbu suture (YZS; Matte et al., 1996; Yin and Harrison, 2000; gray lines in Figure 1). Metamorphic assemblages that have emerged in the center of Qiangtang terrane, were identified as part of a tectonic anticlinorium that is at least $600 \mathrm{~km}$ long and about $300 \mathrm{~km}$ wide, and consists of Upper Paleozoic strata in its core and Jurassic to Upper Cretaceous strata on its northern and southern limbs (Yin and Harrison, 2000; black line and arrows in Figure 1). Systematic mapping of the Coqin area in the north-central part of the Lhasa terrane shows that $\sim 60 \%$ crustal shortening occurred during the Early Cretaceous (Murphy et al., 1997). The collision of the Qiangtang and Lhasa terranes was in the Middle-Late Jurassic ( 175-150 Ma; Chang et al., 1986; Dewey and Shackleton, 1988), and formed the BangongNujiang suture (BNS), which is defined by a wide belt of scattered Jurassic ophiolite and was reactivated by a series of north-dipping thrusts that characteristically cut Tertiary strata (Yin and Harrison, 2000). The Himalaya terrane, that has evolved since the onset of the Indo-Asian collision at about $70 \mathrm{Ma}$ ago, consists of three tectonic slices bounded by three northing-dipping Late Cenozoic fault systems: the main boundary thrust (MBT), the main central thrust (MCT), and the south Tibetan detachment system (STDS), and lies between the Indian shield and Lhasa terrane (Yin and Harrison, 2000).

This study applied 225 broadband seismic stations of Network XR and XF from the IRIS Data Center network. Network XR is the network of Phase III of the INDEPTH project, and Network XF is the Hi-CLIMB project network. The network of Hi-CLIMB stations are distributed as a 800-km-long linear array of broadband seismometers around $85^{\circ} \mathrm{E}$, extending northward from the Ganges basin, across the Himalaya, the YZS, the 


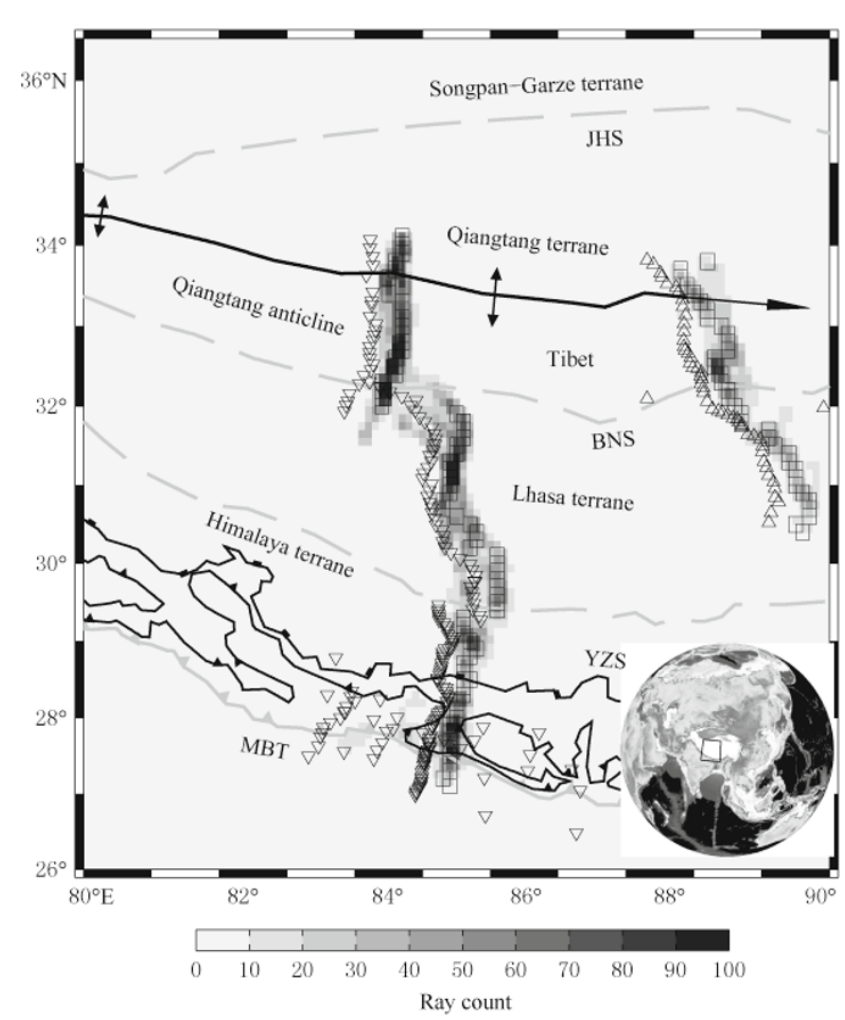

Figure 1 Regional tectonic map of the Tibetan plateau and station distribution of this study showing major suture zones, terranes, fault systems, the dip and plunge of the Qiangtang anticlinorium (black line with arrows) (Yin and Harrison, 2000), stations of different networks (inverted triangles stand for Network XF and Hi-CLIMB stations; triangles for Network XR and INDEPTH III stations), and piercing ray counts per $0.2^{\circ} \times 0.2^{\circ}$ area at $95 \mathrm{~km}$ depth (grayness). The black bins $\left(0.2^{\circ} \times 0.2^{\circ}\right)$, marking the maximum density area of the same latitude, were used to select and stack receiver functions of 90 to $100 \mathrm{~km}$ depth range. Abbreviations: MBT: Main boundary thrust; YZS: Yarlung Zangbu suture; BNS: Bangong-Nujiang suture; JHS: Jinsha-Honghe suture.

Lhasa terranes and the BNS to the center of the Qiangtang anticlinorium (inverted triangles in Figure 1). The INDEPTH III stations are distributed from the central Lhasa terrane to the central Qiangtang terrane along NNW-SSE across the BNS at about $89.5^{\circ} \mathrm{E}$ (triangles in Figure 1).

\section{Data acquisition and processing}

We accessed $\sim 1000$ teleseismic earthquake data with high signal-to-noise ratio $(>3.0)$ from 225 broadband seismic stations as described above from the IRIS Data Center network. We used a time-domain iterative deconvolution approach (Ligorría and Ammon, 1999) to calculate $\mathrm{P}$-wave receiver functions and adopted values of 1.5, 2.5 and 5.0 as Gauss filter factors to clean up high-frequency noise. We used the fitness between the vertical and receiver-function convolution and the radial-component seismogram as the quality control criterion of data, and only selected those receiver functions, which demonstrate a fitness larger than $90 \%$. We eliminated erroneous receiver functions whose wave amplitudes were abnormally large or had negative first arrival peaks. After rejecting bad receiver functions, we finally obtained $\sim 18000$ high-quality ones to generate stacking profiles.

Structural profiles were generated by transferring and applying the time-domain receiver functions to depth-domain structures. Because the Tibetan crustal velocity structure is very complicated and inhomogeneous, it is difficult to migrate receiver function $\mathrm{P}$ - to $\mathrm{S}$-wave phases to accurate depth and position using unreliable velocity models. Here we use the more accurate SEAPS (Sun's East Asia P- and S-wave) (Sun and Toksöz, 2006; Sun et al., 2008) crustal model instead of global models to transform time domain waveform to depth structure.

In making the stacking profiles, receiver functions were usually rearranged according their piercing-points at average Moho depth. This may be inappropriate here due to the immense variance of Moho depth in study area, and could lead to some bias and even artifacts in the images. We gathered receiver functions based on different piercing depths. Each profile consists of nine depth segments. To form each depth segment, receiver functions were rearranged by piercing points at the center depth of each segment, binned with $0.2^{\circ} \times 0.2^{\circ}$, corrected by ray parameters, stacked, and transformed to depth domain. The detailed method is as following:

For each depth segment $(10-20,20-30, \cdots$, 90-100 km), (1) calculate piercing points for each earthquake-station pair assuming the pierce-depth at center depth $(15,25,35,45,55,65,75,85,95 \mathrm{~km})$ of each segment; (2) mesh the study area into $0.1^{\circ}$ grid and count piercing rays in $0.2^{\circ} \times 0.2^{\circ}$ bins centering on each grid (grayness in Figure 1); (3) for each latitude, select receiver functions in the densest piercing-ray bin (e.g. black bins in Figure 1), stack them, and transform them to the depth domain.

After stacking for each depth-segment, we merge stacking segments of each latitude and depth to obtain the final profiles.

When stacking and transforming to the depth domain, we correct the waveform for different ray- 
parameters. The time-depth transformation equation is as following:

$$
\begin{gathered}
t=H\left(\frac{\cos \theta_{\mathrm{S}}}{v_{\mathrm{S}}}-\frac{\cos \theta_{\mathrm{P}}}{v_{\mathrm{P}}}\right)= \\
\frac{H}{v_{\mathrm{P}}}\left(\sqrt{\kappa^{2}-v_{\mathrm{P}}^{2} p^{2}}-\sqrt{1-v_{\mathrm{P}}^{2} p^{2}}\right),
\end{gathered}
$$

where $t$ is the difference in travel time of the P-to-S wave minus the $\mathrm{P}$-wave time, $p$ is the ray parameter, and $\kappa$ is the velocity ratio of $\mathrm{P}$-wave and $\mathrm{S}$-wave.

The average $\mathrm{P}$ - and S-wave velocity of ray-piercing position are calculated from the SEAPS model as

$$
v_{\mathrm{P}}=\frac{\sum_{i} h_{i}}{\sum_{i} \frac{h_{i}}{v_{\mathrm{P} i}}},
$$

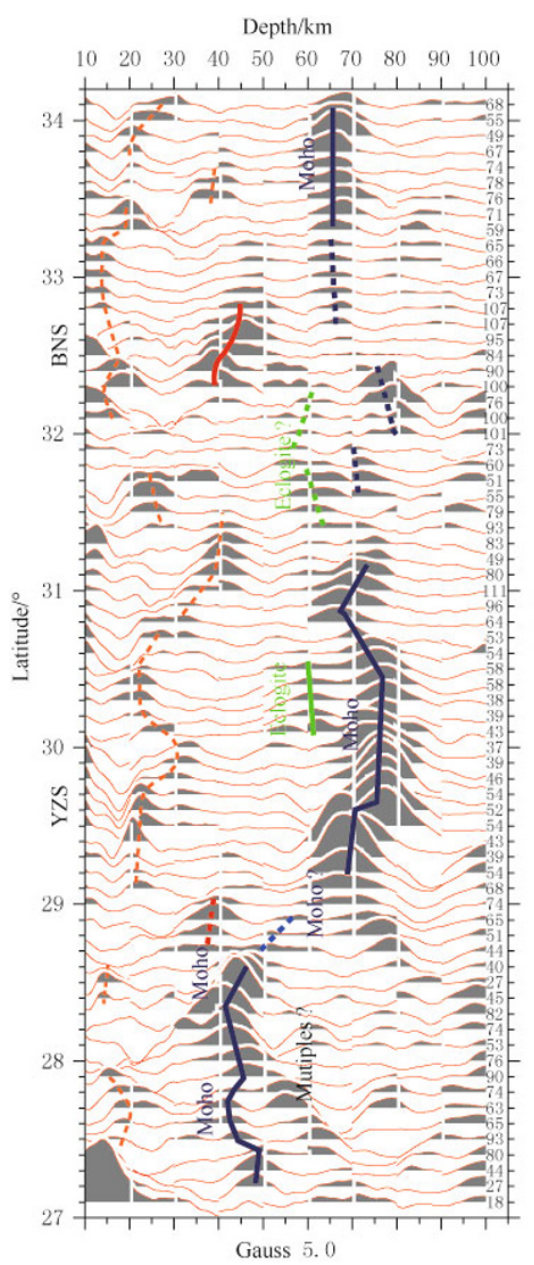

$$
v_{\mathrm{S}}=\frac{\sum_{i} h_{i}}{\sum_{i} \frac{h_{i}}{v_{\mathrm{S} i}}},
$$

where $h_{i}$ and $v_{i}$ are layer thickness and velocity derived from the SEAPS model.

\section{Crustal structure of the central Tibetan plateau}

It is difficult to identify Tibetan crustal structures due to the complex structural nature of the plateau, and its intensive tectonic evolutionary history. Here we present Hi-CLIMB and INDEPTH profiles of three frequencies (Figures 2 and 3). Lower frequency profiles are able to exhibit steady but coarse results. Higher
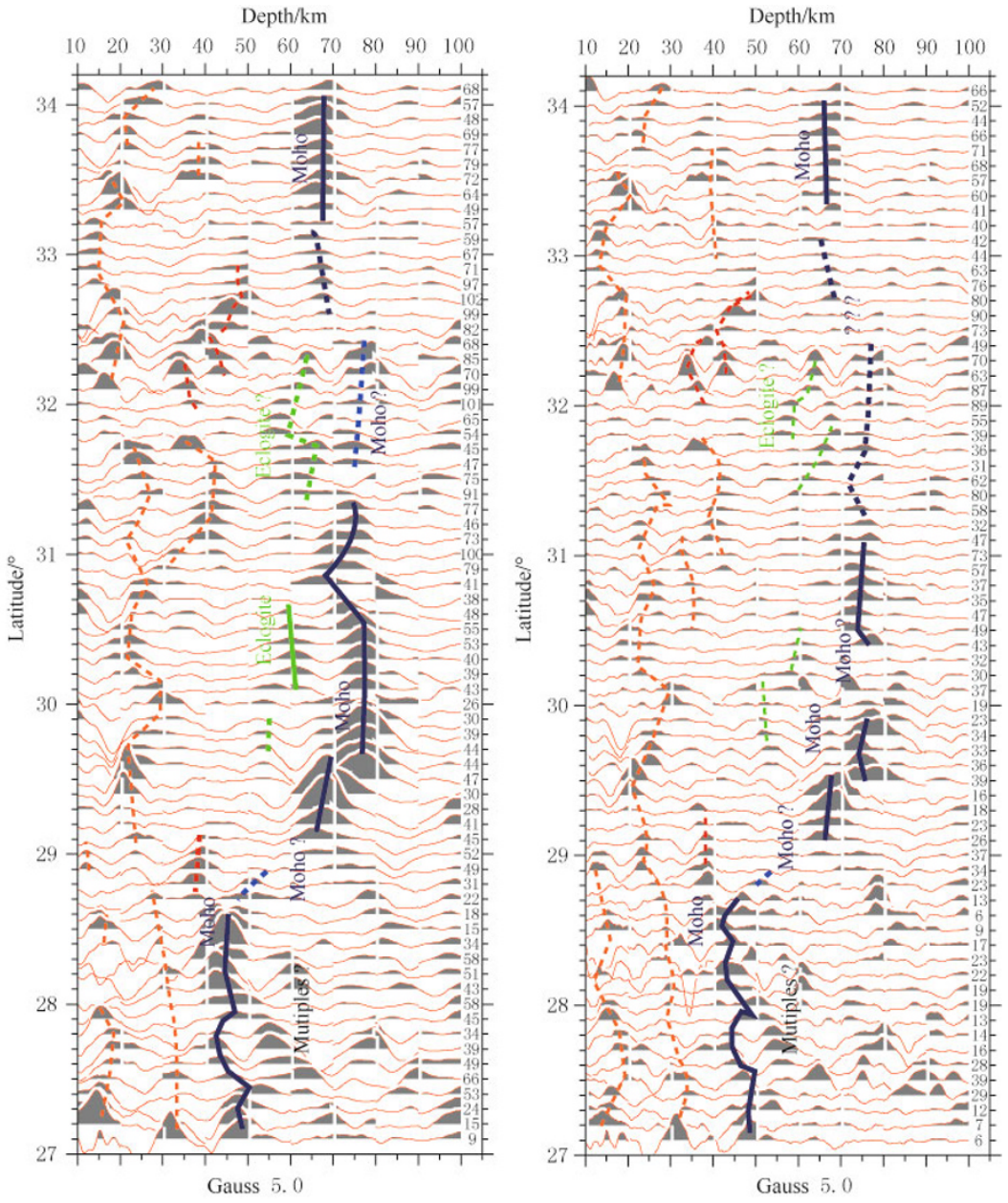

Figure 2 Stacked receiver function images of different frequencies generated from Hi-CLIMB stations (Network XF, inverted triangles in Figure 1) records. The absolute amplitudes were drawn at the same scale. Lines in different colors mark probable crustal interfaces. Blue lines mark probable Moho interfaces. Green and red lines mark probable eclogitic interfaces. Orange lines mark other crustal interfaces. Piercing ray counts of each bin in Figure 1 are listed after each trace. BNS denotes Bangong-Nujiang suture, and YZS denotes Yarlung Zangbu suture. 

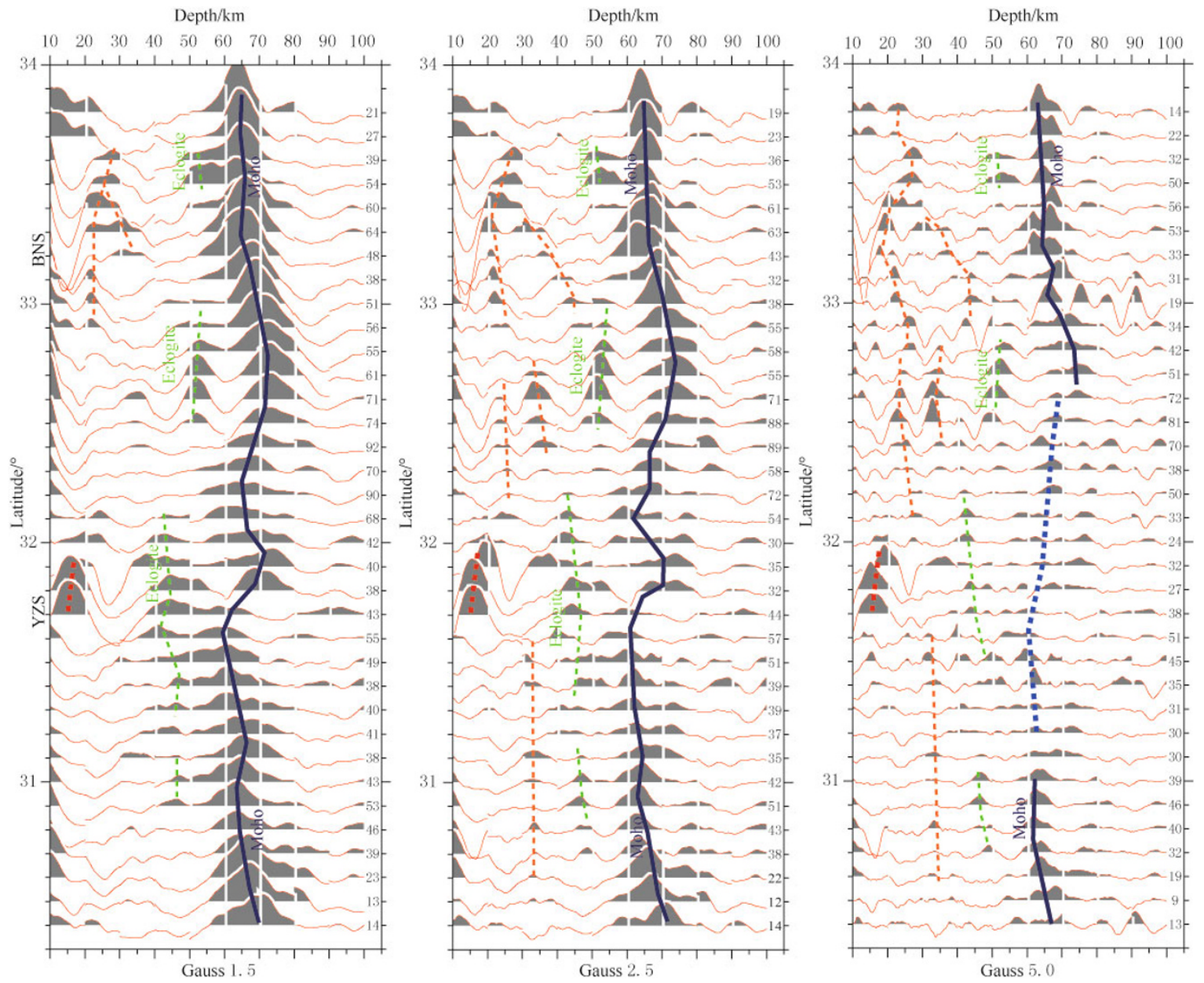

Figure 3 Stacked receiver function images of different frequencies generated from INDEPTH stations (Network $\mathrm{XR}$, triangles in Figure 1) records. The amplitude is drawn at the same scale, and lines in different colors mark probable crustal interfaces. Blue lines mark probable Moho interfaces. Green lines mark probable eclogitic interfaces. Orange lines mark other crustal interfaces. The red line marks the shallow interface with abnormal large impedance. Piercing ray counts of each bin in Figure 1 are listed after each trace. BNS denotes Bangong-Nujiang suture, and YZS denotes Yarlung Zangbu suture.

frequency profiles are able to uncover more detailed structures due to the shorter wavelength, however, weaker signals are easier to contaminate by noise. Combined with three different frequency profiles, we interpret those signals to be consistent in three frequency profiles. According the signal depth, amplitude, peakwidth and continuity of different frequencies, along with other geophysical study results, the Moho interfaces and other possible crustal interfaces were delineated as following.

Due to large impedance between the crust and mantle, the Moho interface usually generates significant P-to-S converted wave, which are easily traced (blue lines in Figure 2). On all Hi-CILMB profiles with different frequencies, the characteristics of the Moho interfaces are similar. The depths of the Moho interfaces show high variance from $40 \mathrm{~km}$ to $80 \mathrm{~km}$. We find that the biggest Moho jump beneath the northern Himalaya terrane is located at about $28.5^{\circ} \mathrm{N}-29.5^{\circ} \mathrm{N}$, where the Moho depth jumps from $\sim 45 \mathrm{~km}$ to $\sim 75 \mathrm{~km}$, which is consistent with an increase in Moho depth under the northern Himalaya predicted by gravity measurements (Lyon-Caen and Molnar, 1985; Cattin et al., 2001) and a receiver function study (Nábělek et al., 2009). However, the amplitudes in our images are different from those of Nábělek. One difference of the processing methods is that we use absolute amplitude instead of relative amplitude, which may be affected by shallower sediment structure and produce inaccuracies in the developed Earth model (Cassidy, 1992). Another difference is that we abandon wave multiples ( $\mathrm{PpPs}$ and $\mathrm{PsPs}$ ), whose sampling distance is 3 to 5 times farther than 
Ps conversions, and which may reflect different structures due to the heterogeneous subsurface in the study area. Our profiles suggest signal amplitude of Moho interfaces have dramatic changes. The strongest amplitudes are found beneath the YZS zone, which indicates very sharp velocity changes between the crust and mantle in this zone. The weakest amplitudes are found beneath the northern Lhasa terrane to southern Qiangtang terrane $\left(\sim 31.5^{\circ} \mathrm{N}-33^{\circ} \mathrm{N}\right)$ and the northern Himalaya terrane $\left(\sim 29^{\circ} \mathrm{N}\right)$, meaning that we observe smooth velocity changes between crust and mantle in these zones. There are three possible reasons why we might observe a smooth impedance-change at the Moho. Firstly, the Moho interface becomes ambiguous because of the mixture of crust and mantle material, caused by violent tectonic movement, which is likely to take place at plate boundaries such as orogenic zones and suture zones. Secondly, the velocity of the upper mantle decreases to crustal velocities, most likely as a result of partial melting, which would also have the effect of decreasing the shear modulus as well as shear wave velocity. However, low velocity zones presented by the 3-D $v_{\mathrm{SV}}$ model from a seismic ambient noise study (Yang et al., 2012) seem to have little correspondence with smooth impedance-change zones identified in this study. Thirdly, increases in crustal velocities to mantle velocities as a result of rock-mass transfer and/or transformation of lower crustal material to denser and higher velocity material (e.g., eclogite; Schulte-Pelkum et al., 2005) may be another reason. This process would be expected to form an addition layer over the Moho. The crustal positive amplitude arrivals (green lines in Figure 2 ), seen at the Lhasa terrane at depths of 60-65 km, imply a high-velocity layer in the lower crust. At the same position, conversions from the Moho are weaker than what we observe in the YZS, which is expected for a reduced velocity contrast as a result of a faster lower crust. Previous studies have shown that the subparallel structure (green solid lines in Figure 2) beneath the middle of the Lhasa terrane is a eclogitic layer (Wittlinger et al., 2009; Nábělek et al., 2009). According to their studies, the $v_{\mathrm{S}}$ variation at the eclogite interface is as high as $\sim 1.1 \mathrm{~km} / \mathrm{s}$ and $v_{\mathrm{S}}$ of the eclogitic layer is $\sim 4.73 \mathrm{~km} / \mathrm{s}$, which has a $v_{\mathrm{S}}$ comparable to olivine. In this case, the $v_{\mathrm{S}}$ contrast between the eclogitic layer and mantle should be very small, which does not agree with the large Ps conversion at the Moho boundary from our observations (the blue lines beneath green solid lines in Figure 2). For this reason, we estimate that the in- creased velocity in the lower crust of Lhasa would not be so much, implying that the partial eclogitization may be less than $50 \%$ in these regions. On the other hand, our observation of strong Ps conversions above absent Moho Ps conversions on the northern Himalayan terrane and the BNS (red lines in Figure 2) at depths of 40-50 km implies very high-velocity layers in the lower crust, which suggests a full eclogitic lower crust.

On all INDEPTH profiles, the depth of the Moho interface varies between $60 \mathrm{~km}$ and $75 \mathrm{~km}$ (blue lines in Figure 3). Our results are shallower than $65-78 \mathrm{~km}$, which was suggested by previous research (Kind et al., 2002), and likely was due to different velocity models we used. Similar to Hi-CLIMB profiles, signal amplitudes of the Moho on INDEPTH profiles diminish near and south of the BNS. The crustal positive amplitude arrivals, seen at a depth of $40-55 \mathrm{~km}$, probably imply the presence of partial eclogitic layers as well. Previous studies have shown that the Indian subduction lithosphere has thrusted northward and reached toward the BNS in the central Tibetan plateau (Kind et al., 2010; Zhao et al., 2010; Zhao et al., 2011). Therefore, the eclogitic layer north of the BNS probably formed due to the collision of the Qiangtang and Lhasa terranes in the Middle-Late Jurassic.

Large-scale conversion to eclogite can result in delamination of the denser material into the mantle, which has been invoked as possible mechanisms to balance the crustal volume deficit (Spain and Hirn, 1997; Johnson, 2002). However, the varying amplitude of Moho signals and distributed eclogitic signals suggest the eclogitization of varying degree is presented under Tibet pervasively. The transition to the eclogite facies requires high pressure but cold temperature conditions, such as a quickly under-thrusted Indian plate beneath the Himalaya. When the eclogite subsequently reached to deeper depth and heated up, it probably partially converts to low-density granulite, which would help buoy up the Tibetan plateau (Le Pichon et al., 1997), and decrease eclogitic degree or/and result in the vanishing of the doublet structure.

Other signals from crustal interfaces, which separate $\mathrm{Si}-\mathrm{Al}$ crust from $\mathrm{Si}-\mathrm{Mg}$ crust, are detected by our images as well (orange lines in Figures 2 and 3). However, due to lower impendence and noise, these signals are more difficultly traced and inconsistent in the profiles of different frequencies. Because of these uncertainties, we do not make further interpretation. 


\section{Conclusions}

We have presented a detailed crustal structure along the Hi-CILMB and INDEPTH III profiles in central Tibet using teleseismic earthquake data. Our structure images show a steep Moho jump beneath northern Himalaya and an undulatory Moho beneath the Tibetan plateau. Meanwhile there are several high velocity layers distributed over the fluctuant Moho, suggesting a full to partial transition to eclogite facies material. Structures near the BNS are significantly different from the core of the Lhasa and Qiangtang terranes, which was probably formed by the collision between these two microcontinents.

Acknowledgements All the people involved in the servicing of the Hi-CLIMB and INDEPTH III network and those who prepared the data set should find here our furthest acknowledgments. We are very grateful to editor and two anonymous reviewers for thoughtful and thorough reviews that improved the manuscript. This study is supported by the project from China Earthquake Administration under grant 201308013 and the National Natural Science Foundation of China (Nos. 40974034, 41174086, 41074052, 41021003).

\section{References}

Besse J and Courtillot V (1988). Paleogeographic maps of the continents bordering the Indian Ocean since the Early Jurassic. J Geophys Res 93(B10): 11 791-11 808.

Cassidy J F (1992). Numerical experiments in broadband receiver function analysis. Bull Seismol Soc Am 82(3): $1453-1474$.

Cattin R, Martelet G, Henry P, Avouac J P, Diament M and Shakya T R (2001). Gravity anomalies, crustal structure and thermo-mechanical support of the Himalaya of central Nepal. Geophys J Inter 147(2): 381-392.

Chang C F, Chen N S, Coward M P, Deng W M, Dewey J F, Gansser A, Harris N, Jin C W, Kidd W, Leeder M R, Li H A, Lin J L, Liu C J, Mei H J, Molnar P, Pan Y, Pan Y S, Pearce J A, Shackleton R M, Smith A B, Sun Y Y, Ward M, Watts D R, Xu J T, Xu R H, Yin J X and Zhang Y Q (1986). Preliminary conclusions of the Royal Society and Academia Sinica 1985 geotraverse of Tibet. Nature 323: 501-507.

Clark M K and Royden L H (2000). Topographic ooze: Building the eastern margin of Tibet by lower crustal flow. Geology 28(8): 703-706.

Chung S L, Chu M F, Zhang Y, Xie Y, Lo C H, Lee T Y, Lan C Y, Li X H, Zhang Q and Wang Y (2005). Tibetan tectonic evolution inferred from spatial and tem- poral variations in post-collisional magmatism. Earth Sci Rev 68(3): 173-196.

Dewey J F, Shackleton R M, Chang C and Sun Y (1988). The tectonic evolution of the Tibetan plateau. Phil Trans $R$ Soc London A 327(1594): 379-413.

England P and Houseman G (1986). Finite strain calculations of continental deformation 2. Comparison with the India-Asia collision zone. J Geophy Res 91(B3): 3 6643676.

Houseman G and England P C (1996). A lithospheric thickening model for the Indo-Asian collision. In: Yin A and Harrison T M eds. Tectonic Evolution of Asia, World and Regional Geology. Cambridge University Press, New York, 3-17.

Johnson M R W (2002). Shortening budgets and the role of continental subduction during the India-Asia collision. Earth Sci Rev 59: 101-123.

Kao H, Gao R, Rau R J, Shi D, Chen R Y, Guan Y and Wu F T (2001). Seismic image of the Tarim basin and its collision with Tibet. Geology 29(7): 575-578.

Kind R, Yuan X, Saul J, Nelson D, Sobolev S V, Mechie J, Zhao W, Kosarev G, Ni J, Achauer U and Jiang M (2002). Seismic images of crust and upper mantle beneath Tibet: Evidence for Eurasian plate subduction. Science 298(5596): 1 219-1 221.

Kind R and Yuan X (2010). Seismic images of the biggest crash on Earth. Science 329(5998): 1 479-1 480.

Kosarev G, Kind R, Sobolev S V, Yuan X, Hanka W and Oreshin S (1999). Seismic evidence for a detached Indian lithospheric mantle beneath Tibet. Science 283(5406): $1306-1309$.

Kumar P, Yuan X, Kind R and Kosarev G (2005). The lithosphere-asthenosphere boundary in the Tien ShanKarakoram region from $\mathrm{S}$ receiver functions: Evidence for continental subduction. Geophys Res Lett 32: L07305.

Kumar P, Yuan X, Kind R and Ni J (2006). Imaging the colliding Indian and Asian lithospheric plates beneath Tibet. J Geophys Res 111: B06308, doi:10.1029/2005JB003930.

Langston C A (1979). Structure under Mount Rainier, Washington, inferred from teleseismic body waves. $J$ Geophys Res 84(B9): 4 749-4 762.

Le Pichon X, Fournier M and Jolivet L (1992). Kinematics, topography, shortening, and extrusion in the IndiaEurasia collision. Tectonics 11(6): 1 085-1 098.

Le Pichon X, Henry P and Goffé B (1997). Uplift of Tibet: from eclogites to granulites - implications for the Andean Plateau and the Variscan belt. Tectonophys 273(12): $57-76$.

Li C, van der Hilst R D, Meltzer A S and Engdahl E R (2008). Subduction of the Indian lithosphere beneath the Tibetan plateau and Burma. Earth Planet Sci Lett 274(1): 157-168.

Ligorría J P and Ammon C J (1999). Iterative deconvolu- 
tion and receiver-function estimation. Bull Seismol Soc Am 89(5): 1 395-1 400.

Lyon-Caen H and Molnar P (1985). Gravity anomalies, flexure of the Indian plate, and the structure, support and evolution of the Himalaya and Ganga Basin. Tectonics 4(6): 513-538.

Matte P, Tapponnier P, Arnaud N, Bourjot L, Avouac J P, Vidal P, Liu Q, Pan Y S and Wang Y (1996). Tectonics of Western Tibet, between the Tarim and the Indus. Earth Planet Sci Lett 142(3-4): 311-330.

Molnar P and Tapponnier P (1975). Cenozoic tectonics of Asia: Effects of a continental collision. Science 189(4201): 419-426.

Murphy M A, Yin A, Harrison T M, Dürr S B, Chen Z, Ryerson F J, Kidd W S F, Wang X and Zhou X (1997). Did the Indo-Asian collision alone create the Tibetan plateau? Geology 25(8): 719-722.

Nábělek J, Hetényi G, Vergne J, Sapkota S, Kafle B, Jiang $\mathrm{M}$, Su H, Chen J, Huang B S and the Hi-CILMB Team (2009). Underplating in the Himalaya-Tibet collision zone revealed by the Hi-CLIMB experiment. Science 325(5946): 1 371-1 374.

Patriat P and Achache J (1984). India-Eurasia collision chronology has implications for crustal shortening and driving mechanism of plates. Nature 311: 615-621.

Patzelt A, Li H, Wang J and Appel E (1996). Palaeomagnetism of Cretaceous to Tertiary sediments from southern Tibet: evidence for the extent of the northern margin of India prior to the collision with Eurasia. Tectonophys 259(4): 259-284.

Powell C M and Conaghan P J (1973). Plate tectonics and the Himalayas. Earth Planet Sci Lett 20(1): 1-12.

Royden L H, Burchfiel B C and van der Hilst R D (2008). The geological evolution of the Tibetan plateau. Science 321(5892): 1 054-1 058.

Spain M and Hirn A (1997). Seismic structure and evidence for eclogitization during the Himalayan convergence. Tectonophys 273(1): 1-16.

Schulte-Pelkum V, Monsalve G, Sheehan A, Pandey M R, Sapkota S, Bilham R and Wu F (2005). Imaging the Indian subcontinent beneath the Himalaya. Nature 435(7046): 1 222-1 225.

Singh A and Kumar M R (2009). Seismic signatures of detached lithospheric fragments in the mantle beneath eastern Himalaya and southern Tibet. Earth Planet Sci Lett 288(1): 279-290.

Sun Y and Toksöz M N (2006). Crustal structure of China and surrounding regions from $\mathrm{P}$ wave traveltime tomography. J Geophys Res 111: B03310.

Sun Y, Toksöz M N, Pei S and Morgan F D (2008). The layered shear-wave velocity structure of the crust and uppermost mantle in China. Bull Seismol Soc Am 98(2): $746-755$.

Tseng T L, Chen W P and Nowack R L (2009). Northward thinning of Tibetan crust revealed by virtual seismic profiles. Geophys Res Lett 36(24): L24304.

Tapponnier P, Xu Z Q, Roger F, Meyer B, Arnaud N, Wittlinger G and Yang J S (2001). Oblique stepwise rise and growth of the Tibet Plateau. Science 294(5547): 1 6711677 .

Wittlinger G, Farra V, Hetényi G, Vergne J and Nábělek J (2009). Seismic velocities in Southern Tibet lower crust: A receiver function approach for eclogite detection. Geophys J Inter 177(3): 1 037-1 049.

Wittlinger G, Vergne J, Tapponnier P, Farra V, Poupinet G, Jiang M, Su H, Herquel G and Paul A (2004). Teleseismic imaging of subducting lithosphere and Moho offsets beneath western Tibet. Earth Planet Sci Lett 221(1): $117-130$.

Yang Y, Ritzwoller M H, Zheng Y, Shen W, Levshin A L and Xie Z (2012). A synoptic view of the distribution and connectivity of the mid-crustal low velocity zone beneath Tibet. J Geophys Res 117: B04303.

Yi Z, Huang B, Chen J, Chen L and Wang H (2011). Paleomagnetism of Early Paleogene marine sediments in southern Tibet, China: Implications to onset of the India-Asia collision and size of Greater India. Earth Planet Sci Lett 309(1): 153-165.

Yin A and Harrison T M (2000). Geologic evolution of the Himalayan-Tibetan orogen. Ann Rev Earth Planet Sci 28(1): 211-280.

Zhao J, Yuan X, Liu H, Kumar P, Pei S, Kind R, Zhang Z, Teng J, Ding L, Gao X, Xu Q and Wang W (2010). The boundary between the Indian and Asian tectonic plates below Tibet. Proc Natl Acad Sci 107(25): 11 229-11 233.

Zhao W, Kumar P, Mechie J, Kind R, Meissner R, Wu Z, Shi D, Su H, Xue G, Karplus M and Tilmann F (2011). Tibetan plate overriding the Asian plate in central and northern Tibet. Nature Geoscience 4(12): 870-873.

Zhang Z, Yuan X, Chen Y, Tian X, Kind R, Li X and Teng J (2010). Seismic signature of the collision between the east Tibetan escape flow and the Sichuan Basin. Earth Planet Sci Lett 292(3): 254-264. 